\title{
Insulin Autoimmune Syndrome, IAS (Hirata disease) Case report
}

\section{Ganesh Chockalingam*, Aaron Simpson, Faseeha C Peer, J Dennis Wilson. Endocrinology unit , The Canberra Hospital, ACT and Australian National University.}

Nandini Shankara Narayana, Roderick Clifton-Bligh. Endocrinology unit, Royal North Shore Hospital (RNSH), Sydney, NSW and University of Sydney

*The Sutherland \& St George Hospitals, Sydney, NSW, Australia.

\section{Introduction}

Insulin Autoimmune Syndrome was first described in 1973 by Hirata, characterised by recurrent spontaneous postprandial hypoglycaemia.

Serum insulin concentrations are extremely high associated with elevated insulin auto antibodies.

There have been more than 170 cases reported worldwide. We report the first case of IAS in Australia.

The incidence of IAS in Caucasians is onetenth of that in Japanese populations. The peak age at onset is 60-69 years with no gender difference. Approximately $82 \%$ of IAS patients have a spontaneous remission.

Insulinomas are the most prevalent cause of hyperinsulinemic hypoglycaemia in Caucasians.

Primary investigation is always focused on their localization followed by surgery.

\section{Case Report}

A 81 year old female (of Argentinean heritage) presented with a three month history of progressively worsening symptoms of intermittent, late postprandial diaphoresis, tremors, palpitations, dizziness and confusion.

Symptoms improved with the administration of sugary drinks and other caloric intake resulting in a weight gain of 3 kg over 2 months.

At presentation blood glucose level (BGL) was $1.2 \mathrm{mmol} / \mathrm{L}$.

She required continuous $50 \%$ dextrose to maintain BGL above $6-7 \mathrm{mmol} / \mathrm{L}$.

When her plasma glucose measured $1.9 \mathrm{mmol} / \mathrm{L}$, serum insulin was elevated $>$ $2400 \mathrm{mU} / \mathrm{L}(<27)$, C-peptide $11.7 \mathrm{nmol} / \mathrm{L}$ (0.4-1.5).

Sulphonylurea screening was negative.

\section{Management}

- Abdominal CT, MRI and a GalliumDotatate PET scan all failed to confidently identify an insulinoma.

- $\quad$ An endoscopic ultrasound found an $8 \mathrm{~mm}$ lesion thought to be a lymph node adjacent to the pancreas.

- $\quad$ Selective arterial calcium stimulation and hepatic venous sampling demonstrated high insulin concentrations across the pancreas without a gradient (Table1).

- $\quad$ On the basis of the endoscopic ultrasound findings, laprotomy with intraoperative ultrasound failed to identify an insulinoma; biopsy of the pancreatic tail showed normal islet cells.

- $\quad$ She developed a fistula post-operatively with a chylous ascitic leak requiring rectal sheath suture.

- The diagnosis of Hirata disease was made on demonstration of elevated Insulin auto antibodies at $>50 \mathrm{U} / \mathrm{L}(<0.3)$.

- $\quad$ She was treated with Prednisone starting at $50 \mathrm{mg}$ which was tapered over 12 weeks to a maintenance dose of $5 \mathrm{mg}$.

She was weaned off steroids after 5 months. No hypoglycaemic episodes since then. Fasting glucose 4.0, Insulin 13, Proinsulin 13.3pmol/L, C-peptide 1.1 (all normal). Insulin antibodies $12.47 \mathrm{U} / \mathrm{ml}$ $(<0.3)$ and falling.

\begin{tabular}{|c|c|c|c|c|}
\hline \multirow{2}{*}{ Artery } & \multicolumn{4}{|c|}{ Time (seconds) } \\
\cline { 2 - 5 } & 0 & 30 & 60 & 120 \\
\hline Mesenteric & 3626 & 3842 & 4004 & 3724 \\
\hline Distal Splenic & 3855 & 3974 & 3943 & 3897 \\
\hline $\begin{array}{c}\text { Proximal } \\
\text { Splenic }\end{array}$ & 3906 & 4211 & 3826 & 3919 \\
\hline \begin{tabular}{c} 
Gastroduodenal \\
\hline Hepatic
\end{tabular} & 3892 & 3958 & 4188 & 4126 \\
\hline Insulin level in peripheral blood $3851 \mathrm{mlU} / \mathrm{L}$ & 4028 \\
\hline
\end{tabular}

Table 1. Hepatic venous Insulin measurements ( $\mathrm{mU} / \mathrm{L}$ ) following selective arterial calcium stimulation.

\section{Discussion}

- The postulated mechanism behind Insulin Autoimmune Syndrome (Hirata Disease) is that antibodies directed against insulin disrupt the normal relationship between glucose and insulin.

- The buffering effect of antibodies results in binding and release of secreted insulin out of synchrony with the prevailing glucose concentration leading to severe postprandial hypoglycaemia.

- $\quad$ Free insulin levels are normal though bound (total) levels are high. Altered insulin kinetics post glucose tolerance testing is often observed sometimes with a diabetic glycaemic pattern.

- $\quad$ Although not evident in our patient development of IAS in some individuals has been associated with exposure to sulfhydryl compounds. These compounds are thought to interact with disulphide bonds rendering insulin more immunogenic.

- IAS is strongly associated with HLA class II alleles: DRB1*0406/ DQA1*0301/ DQB1*0302.

- The insulin antibodies of IAS patients are reportedly of the IgG class of wide distribution from $\operatorname{lgG}_{1}$ to $\operatorname{lgG}_{4}$

- $\quad$ Our case highlights an important differential diagnosis and the need to measure insulin antibodies in such cases, to avoid potentially unnecessary surgery.

Patients are best treated with conservative support and possibly immunosuppressive therapy.

\section{References}

Hirata $\mathrm{Y}$, Ishizu $\mathrm{H}$, Ouch $\mathrm{N}$, et al. Insulin autoimmunity in a case of spontaneou hypoglycaemia.J Jpn Diabetes Soc 1970;13:312-19.

Hirata $Y$ U Pract 1994:24(Suppl):S153-7. 1999;28(3):603-18.

Ma WY, Won JG, Tang KT, Lin HD. Severe hypoglycemic coma due to insulin autoimmune J Chin Med Assoc 2005;68(2):82-6.

Uchigata Y, Kuwata S, Tokunaga K, et al. Strong association of insulin autoimmun

Uchigata Y, Eguchi Y, Takayama-Hasumi S, Hirata Y. The immunoglobulin class, the subclass and the ratio of kappa:lambda light chain of autoantibodies to human insulin in

Cryer PE. in autoimmune hypoglycemia. J Clin.Invest. 1979;63(5):1050-9. Hypoglycemia. Kasper DL, Fauci AS, Longo DL, Braunwald E, Hauser SL, Jameson JL, eds. 17th ed.
Harrison's Principles of Internal Medicine. New York: McGraw-Hill:2008. Chapter 339: 2305-13. AH, et at. Characteration of circulating insulin and proinsulin binding antibodies 